\title{
Experience in the treatment of meningitis associated with health care in pediatric patients
}

\author{
Mónica C. Mercado ${ }^{*}$, Martín Guerrero-Becerra², Lorelay Gutiérrez-Oliva1 ${ }^{1}$ Pedro A. Martínez-Arce², \\ Mariana Merlo-Palomera², and Luis Á. Arredondo-Navarro ${ }^{1}$ \\ ${ }^{1}$ Pediatric Neurosurgery; ${ }^{2}$ Pediatric Infectology. Hospital Civil de Guadalajara “Fray Antonio Alcalde”, Universidad de Guadalajara, Guadalajara, Mexico
}

\begin{abstract}
Objective: The objective of the study was to describe our clinical experience in meningitis associated with health care (MAHC). Methods: A retrospective study included pediatric patients, with MAHC, from 2010 to 2017. Parametric variables were evaluated by media, standard deviation, media and interquartile range. Non-parametric variables were described by reasons and proportions, Chi-square IC 95\%. Significant variables $(p<0.005)$ were evaluated by bivariate logistic regression model to identify related risks for adverse evolution. We obtained the approval of the research ethics committee of our hospital for publication of this data. Results: A total of 114 cases of MAHC in children were analyzed. There were Gram-negative bacilli $(62.6 \%)$ and ESBL producers (42.4\%). Mortality was higher amongst cases exposed to more than three antibiotics $O R=5.50$ (IC 95\%, LI 0.996, LS 30.36) sig 0.050 mortality correlation 0.847. Conclusions: Gram-negative bacteria are frequent in MAHC, mortality was correlated to exposition more than three antibiotics.
\end{abstract}

Key words: Meningitis. Acinetobacter baumannii. Antibiotics.

\section{Experiencia en tratamiento de meningitis y ventriculitis asociada a los cuidados de la salud en pacientes pediátricos}

\section{Resumen}

Objetivo: Describir experiencia clínica en tratamiento de MACS. Métodos: Estudio retrospectivo en pacientes pediátricos con MACS durante 2010 a 2017. Variables paramétricas evaluadas con medias, desviación estándar y rango intercuartil. Variables no paramétricas por razones, proporciones, Chi cuadrada IC 95\%. Variables significativas $(p<0.005)$ evaluadas por modelo de regresión logística bivariada para identificar riesgos de evolución adversa. Resultados: 114 casos de MACS en niños con predominio de gramnegativos (62.6\%) BLEE (42.4\%). Mortalidad mayor entre casos expuestos a más de tres antibióticos OR = 5.50 (IC 95\%, LI 0.996, LS 30.36) sig. 0.050, correlación con mortalidad 0.847. Conclusiones: Las bacterias gramnegativas son más frecuentes en MACS, con mortalidad correlacionada a exposición con más de tres antibióticos.

Palabras clave: Meningitis. Acinetobacter baumanii. Antibióticos.

Correspondence:

*Monica Cecilia Mercado

E-mail: monicauribe_99@yahoo.com.mx DOI: 10.24875/RMN.M19000050
Available online: 04-12-2019 Rev Mex Neuroci. 2019;20(6):255-261 www.revmexneurociencia.com 1665-5044/@ 2019 Academia Mexicana de Neurología A.C. Published by Permanyer. This is an open access article under the CC BY-NC-ND license (http:// creativecommons.org/licenses/by-nc-nd/4.0/). 


\section{Introduction}

Meningitis associated with health care (MAHC) or nosocomial origin, usually of bacterial etiology, can be a consequence of invasive procedures: craniotomy (0.8-1.5\%) internal ventricular catheters $(4-17 \%)$ or external $(8 \%)$, lumbar puncture ( $x 1$ every 50,000$)$, intrathecal infusion of medications, spinal anesthesia (0.8$5 \%)$, complicated head injury (1.4-25\%), or metastatic infection in patients with acquired bacteremia ${ }^{1-3}$. MAHC episodes can be diagnosed during the hospitalization period and up to one year after its onset. It is often produced by multiresistant bacteria, unlike the bacteria that cause community meningitis 4 .

In recent years, there has been a reported decrease in the incidence of MAHC, although report of permanent sequels and frequent association with coagulase-negative Staphylococcus persists; nevertheless, participation of Klebsiella pneumoniae, Pseudomonas aeruginosa, Escherichia coli, and Acinetobacter baumannii are relevant; often multidrug-resistant (MDR), especially related to use of broad-spectrum antibiotics ${ }^{5-9}$.

The term MDR refers to the expression of bacterial resistance to at least one agent in $\geq 3$ antibiotic categories. We define a bacterium as extra drug resistant (XDR), when it is not susceptible to more than one antimicrobial agent in at least two antibiotic categories. Resistant bread (PDR) refers to bacterial expression of resistance to all antibiotic categories; particularly, values of minimum inhibitory concentration (MIC) are more useful than category of sensitive, intermediate, or resistant ${ }^{10}$.

Mortality related to MAHC ranges from $9 \%$ to $33 \%$ depending on the causative agent ${ }^{11,12}$. The objective of this study is to describe our clinical experience in $\mathrm{MAHC}$ treatment through the evolution of cases.

\section{Methods}

We carried out a retrospective, descriptive study, between 2010-2017. All pediatric patients hospitalized with a diagnosis suggestive of MAHC in the pediatric division of the Civil Hospital of Guadalajara "Fray Antonio Alcalde" were included in a non-randomized sample (for convenience).

Hospital Civil de Guadalajara Fray Antonio Alcalde, a 1000-bed it is a tertiary care teaching hospital. The hospital provides services to the Jalisco state and its capital, Guadalajara, the second-largest city in Western Mexico, as well as to surrounding states. The hospital consists of adult and pediatric beds. All of the pediatric units are located in one building. There are two neonatal intensive care units (ICUs) and one pediatric ICU. In 2018, there were 7398 patients discharged from the pediatric ward; 300 patients were submitted to neurochirugica treatment.

Patients who met the clinical and laboratory criteria issued by the Centers of Disease Control and Prevention (CDC)'s National Healthcare Safety Network of 2017 (NHSN), and the official Mexican Standard of Epidemiology for Disease Prevention and Control NOM-026 SSA2-1998 were included in the study.

We review patients from 1 month to 14 years and 11 months of age who, having undergone some neurosurgical procedure such as placement of Ventricular Peritoneal Shunt Valve (VPSV), drainage of hematoma, biopsy or resection of brain tumor, among other procedures without other evident focus of infection. They developed meningitis data in the following 14 days and up to 1 year after placement of cerebrospinal fluid (CSF) drainage devices, which were also accompanied by MAHC definition.

\section{Definition}

According to the Meningitis and Ventriculitis Management Guidelines of 2017 CDC/NHSN associated with health care are defined, as a patient with bacterial growth in CSF culture, or a patient with at least two signs and symptoms of fever $>38^{\circ} \mathrm{C}$ or hypothermia $<36^{\circ} \mathrm{C}$, headache, apnea, bradycardia, irritability, cranial or meningeal signs, in addition to abnormal analysis of CSF cytochemistry (hyperproteinorrachy, hypoglycorrhachia, and hypercellularity for central laboratory ranges); organisms seen in Gram-stain, bacteria grown in CSF and blood.

Demographic data, comorbidities, clinical manifestation, as well as microbiological and radiological reports of patients, were recorded together with the antibiotic treatment and its duration. Bacterial isolates in blood and CSF as well as the determination of bacterial antibiotics sensitivity were analized by antibiogram performed by VITEK 2 automated method. Durham California, based on the Clinical and Laboratory Standards Institute (CLSI) formerly the National Committee for Clinical Laboratory Standards as well as the final evolution of each case such as: therapeutic failure, cure, death, relapse or reinfection, were evaluated by at least two infectious pediatricians and the information of cases was registered on an Excel database and analyzed by means of Statistical Package for the Social Sciences IBM SPSS 23.0 
Table 1. Demographic characteristics in 114 episodes of nosocomial meningitis

\begin{tabular}{|c|c|c|c|c|}
\hline Variable & Value (\%) & Media & Desv. Std. & Inter quartil range \\
\hline Age months & & 45.7 & 31.9 & 37.5 \\
\hline $\begin{array}{l}\text { Male } \\
\text { Female }\end{array}$ & $\begin{array}{l}49(43) \\
65(57)\end{array}$ & & & \\
\hline Hospital stay & & 46 & 32 & 35 \\
\hline CVC* time & $96(84.2)$ & 24 & 21 & 34 \\
\hline Previous antibiotics & $82(72)$ & 3 & 3.1 & 3 \\
\hline VPSV** (days postinsertion) & $57(50)$ & 79 & 156 & 90 \\
\hline Ventriculostomy (duration days) & $63(55)$ & 6 & 8.5 & 10 \\
\hline Neurochirurgic procedure & $60(52.6)$ & & & \\
\hline CSF fistula $^{\dagger}$ & $20(17.5)$ & & & \\
\hline $\begin{array}{l}\text { Agents in CSF } \\
\text { Gram-negative bacteria } \\
\text { Gram-positive bacteria } \\
\text { Candida } \\
\text { Polymicrobial } \\
\text { Negative }\end{array}$ & $\begin{array}{c}59(51.7) \\
33(29) \\
4(3.5) \\
7(6.1) \\
11(10.5)\end{array}$ & & & \\
\hline Leucocytes $\left(\times 10^{9}\right)$ & & 14.500 & 6.869 & 10610 \\
\hline Plaquetas $\left(\times 10^{9}\right)$ & & 453.254 & 155.783 & 256.700 \\
\hline $\mathrm{CRP}^{\ddagger}(\mathrm{mg} / \mathrm{dL})$ & & 96.6 & 102.1 & 144.6 \\
\hline $\mathrm{PCT}^{\S}(\mathrm{mmol})$ & & 9.3 & 27.7 & 3.32 \\
\hline CSF glucose (g/L) & & 29.6 & 27.5 & 39 \\
\hline CSF protein $(\mathrm{g} / \mathrm{L})$ & & 8.1 & 2.4 & 0.694 \\
\hline CSF cells & & 3851 & 16587 & 432 \\
\hline
\end{tabular}

*Central venous catheter.

** Ventricular peritoneal shunt valve.

${ }^{\dagger}$ Cerebrospinal fluid.

₹C-reactive protein.

sprocalcitonin.

\section{Ethics}

Standard treatment for nosocomial meningitis was administered to all patients. The study was approved for its execution and publication by the research ethics committee of the Civil Hospital of Guadalajara "Fray Antonio Alcalde" with registration number 026/18.

\section{Statistic analysis}

Parametric variables were evaluated with means, standard deviation, and interquartile range. Non-parametric variables were described by means of ratios, proportions, compared with Chi-square $95 \% \mathrm{Cl}$. All significant variables $(p<0.05)$ were subjected to a bivariate logistic regression model, to identify risk factors related to adverse evolution.

\section{Results}

\section{Demographics}

Between 2010 and 2017, we collected clinical data from 118 episodes of MAHC from 86 patients. We exclude four cases due to insufficient data.

Included patient's ages were from 1 to 200 months of age in their majority; they were carriers of meningitis associated with VPSV (44/51.7\%).

Once the MAHC diagnosis was made, the shunt device was removed within the next 24-72 hours; in each case the patients were subsequently subjected to the placement of an external CSF device.

Change of ventriculostomy was carried out every 7-10 days, until obtaining bacterial negativization, with subsequent resolution of infectious process, for 
Table 2. Evolution of 114 cases of MACS according to the type of agents isolated in CSF

\begin{tabular}{|c|c|c|c|c|c|c|}
\hline \multirow[t]{2}{*}{ Etiology } & Healing & Reinfection & Death & \multicolumn{2}{|c|}{ Death OR } & \multirow[t]{2}{*}{ Total } \\
\hline & n (\%) & n (\%) & n (\%) & & & \\
\hline $\begin{array}{l}\text { Gram-positive } \\
\text { CNS } \\
\text { MSSA } \\
\text { MRSA } \\
\text { Enterococcus }\end{array}$ & $\begin{array}{c}11(50) \\
0 \\
2(50) \\
7(63.6)\end{array}$ & $\begin{array}{c}6(27.3) \\
1(25) \\
2(50) \\
2(18.2)\end{array}$ & $\begin{array}{c}3(13.6) \\
3(75) \\
0 \\
1(9)\end{array}$ & $\begin{array}{c}0.78 \\
5.1 \\
0.52\end{array}$ & $\begin{array}{c}0.21-2.03 \\
2.50-10.64 \\
0.08-3.46\end{array}$ & $\begin{array}{c}22(19.3) \\
4(3.5) \\
4(3.5) \\
11(9.7)\end{array}$ \\
\hline Candida & $4(66.6)$ & $1(16.6)$ & 1 (16.6) & 1 & $0.27-8.78$ & $6(5.2)$ \\
\hline $\begin{array}{l}\text { Gram-negative } \\
\text { GNB MR } \\
\text { GNB ESBL }\end{array}$ & $\begin{array}{c}16(50) \\
13(46.4)\end{array}$ & $\begin{array}{l}11(34.4) \\
10(35.7)\end{array}$ & $\begin{array}{l}6(18.8) \\
3(10.7)\end{array}$ & $\begin{array}{l}1.18 \\
0.57\end{array}$ & $\begin{array}{l}0.49-2.84 \\
0.18-1.83\end{array}$ & $\begin{array}{c}32(28) \\
28(24.6)\end{array}$ \\
\hline Other & $2(28.6)$ & $3(42.9)$ & $2(28.6)$ & 6.29 & $0.52-2.68$ & $7(6.1)$ \\
\hline Total & 48 (42.1) & $36(31.6)$ & 19 (16.6) & & & $114(100)$ \\
\hline
\end{tabular}

CNS: central nervous system; MSSA: Staphylococcus aureus sensitive methicillin; MRSA: methicillin-resistant Staphylococcus aureus, GNB MR: gram-negative bacteria meropenem resistant; GNB ESBL: gram-negative bacteria extended-spectrum beta-lactamase producer.

replacement of a new CSF derivation system, when it was necessary.

Two-thirds of patients received antibiotics before admission for their treatment, on average three antibiotics; $80 \%$ of children required antibiotics infusion through central venous catheter, 23 days on average (Table 1).

\section{Treatment and evolution}

We started an antibiotic scheme guided by a Gram stain of CSF. According to our epidemiology, included for treatment vancomycin and cefepime prescribed at weight and meningeal doses.

In case not having growth in the first CSF culture, treatment was directed based on Gram-stain findings and subsequent CSF cultures, taking into account in addition, results of blood cultures for its final classification as Gram-positive bacterial meningitis, Gram-negative bacterial meningitis, mixed bacterial meningitis or by Candida species.

Single or polymicrobial etiology, and consistent on bacterial or yeast growth were obtained from a first CSF culture on $89.5 \%$ of the samples.

Bacteremia associated with meningitis was isolated in $28 / 100$ cases, but only $7 \%(8 / 28)$ of those were related to the same causative agent. Bacteremia of a different etiology associated with catheter was considered as a coinfection with meningitis.

We obtained an isolation of $71 \mathrm{Gram}$-negative strains $(62.6 \%)$. Derived from antibiotic resistance phenotype producing extended-spectrum beta-lactamases (ESBL) in Gram-negative bacteria, these strains received meropenem alone or in combination with rifampicin. Two strains of Elizabethkingia meningoseptica were resistant to vancomycin and treated with trimethoprim/ sulfamethoxazole.

The most common Gram-negative agent in meningitis cases was $A$. baumannii 30 (42.25\%), all of these cases were considered as a therapeutic failure secondary to meropenem resistance.

In addition, 15 cases (21.1\%) of Gram-negative bacterial infection, among them: $P$. aeruginosa, $K$. pneumoniae, and E. coli; they did not show clearing of CSF in more than 10 days of treatment also with clinical symptoms, they were considered with therapeutic failure to cefepime and meropenem, even though the antibiogram showed sensitivity to meropenem.

All these cases received colistimethate intravenously at a dose of $10 \mathrm{mg} / \mathrm{kg}(125,000 \mathrm{IU})$, and intrathecal at a dose of $10 \mathrm{mg} / \mathrm{kg}$ of impregnation followed by $5 \mathrm{mg} / \mathrm{kg}(75,000 \mathrm{IU})$ per day, in addition to oral rifampicin, until CSF clearing.

Among the Gram-positive bacteria, a strain of Enterococcus faecium was resistant to vancomycin and linezolid; it received 4 weeks of treatment with daptomycin. Finally, four cases with meningitis due to methicillin-sensitive Staphylococcus aureus (MSSA) were treated with vancomycin/rifampicin combination for 20 days, on average 16 days and sensitivity to vancomycin with a MIC $<1 \mu \mathrm{g} / \mathrm{mL}$, all cases were coinfected 
by Gram-negative nosocomial agents producing ESBL or by fungemia.

Distribution of cure rate, death, and reinfection outcome between different bacterial and fungal etiologies was similar, no differences were found by means of Chi-square analysis (Table 2).

\section{Complications}

In 51 episodes (44.7\%), we recorded at least one nosocomial acquisition coinfection, there was predominance of catheter-associated bacteremia $(28 / 24.6 \%)$, two of them complicated with endocarditis, and two with fungemia.

Other complications included: intra-cerebral abscesses or septate ventriculitis $29(25.4 \%)$, azoate elevation $11(10 \%)$, and transaminasemia $15(22.1 \%)$. These complications were prevalent among Gram-positive meningitis group; they were treated with vancomycin, which returned at normal levels after the end of antibiotic treatment.

After MAHC diagnosis, we found neurological sequelae in $68(83.5 \%)$, all of them were patients in whom hemorrhages or intra-cerebral infarctions were associated, epilepsy of recent onset and cognitive deterioration, blindness or deafness. The evolution of cases is shown in table 2 .

\section{Microbiological characteristics of isolated agents}

We were able to identify on the first CSF sample of the 114 episodes of meningitis: four species of Candida (3.5\%), none of them resistant to azoles, and amphotericin B or caspofungin 59 (51.7\%).

The most frequent bacterial isolates in CSF were Gram-negative ESBL-producing phenotype 25 (42.4\%). Enterobacter cloacae, Escherichia coli and Pseudomonas aeruginosa were the most prevalent strains. Thirty one $(52.5 \%)$ bacterial strains with carbapenemase-producing phenotype, $K$. pneumoniae, $P$. aeruginosa, Enterobacter cloacae, and $A$. baumannii, they had $39 \%$ share (23) of these isolates, a MIC for colistimethate minimum 1 and maximum $16 \mu \mathrm{g} / \mathrm{ml}$, two strains were $\mathrm{XDR}$, and the rest MDR.

As of 2010, resistance to meropenem of Gram-negative bacteria was determined through the resistance to antibiotics of all classes, by means of the antibiogram and relation with the lack of CSF bacterial clearance, in addition to persistent symptomatology of MAHC, in all cases of etiology by $A$. baumannii.

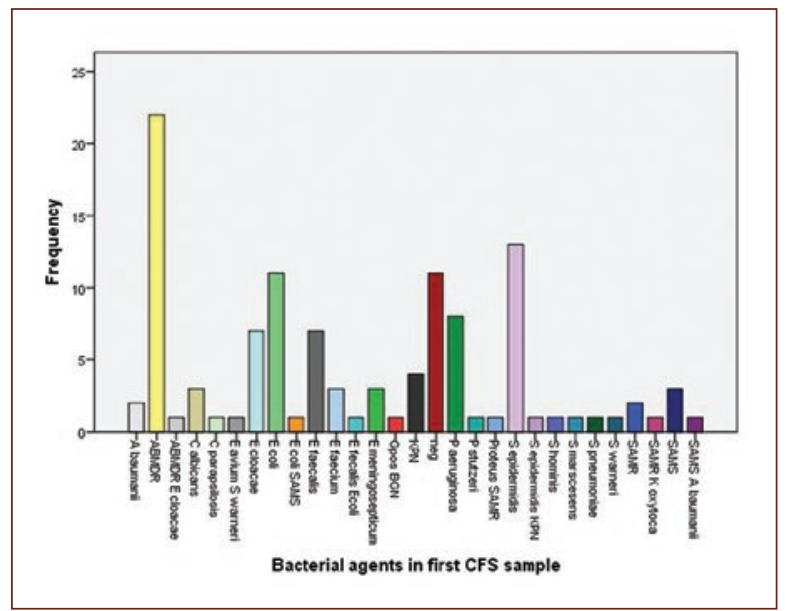

Figure 1. Agents isolated in cultures of first CSF of 114 episodes of MAHC.

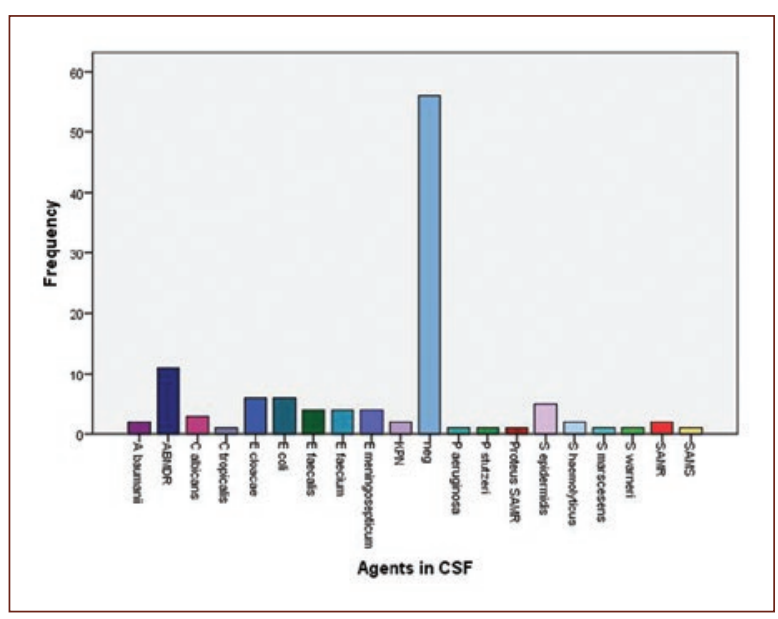

Figure 2. Agents isolated in CSF cultures following 114 episodes of MAHC.

Among Gram-negative bacterial isolates, resistance to carbapenems was frequently the second phenotype found among strains of $K$. pneumoniae, $P$. aeruginosa, Enterobacter cloacae, and $A$. baumannii, responsible for $30(81 \%)$ of cases in this group, with MIC for colistimethate minimum 1 and maximum $16 \mu \mathrm{g} / \mathrm{ml}$, two strains were XDR and the rest MDR.

We identified 37 (32.5\%) Gram-positive bacteria and in 9 samples of CSF (7.9\%) growth with two simultaneous agents that included ABMDR or ESBL-producing Gram-negative bacteria and Candida species sensitive to amphotericin B.

Eleven (9.6\%) cultures were reported as negative, although in Gram stain bacteria were seen, probably due to antibiotics use before diagnosis (Fig. 1). 


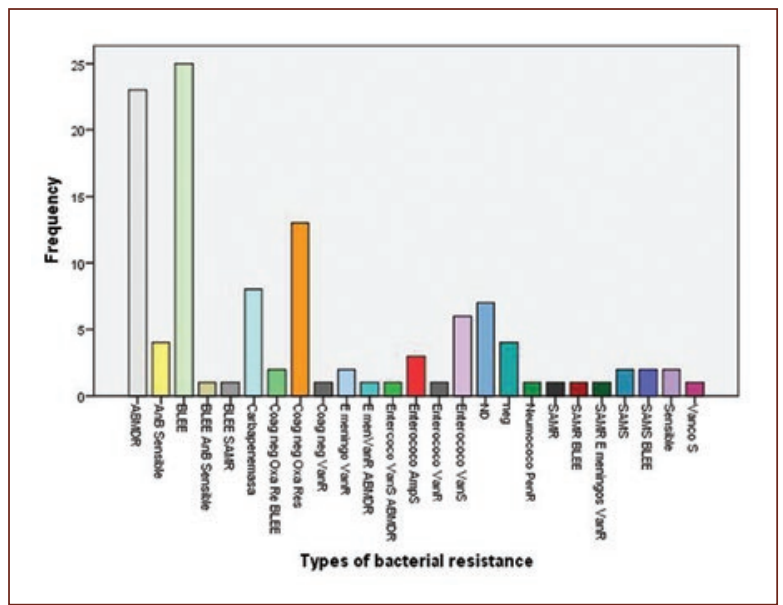

Figure 3. Antibiotic resistance phenotype in 102 strains isolated from the first CSF in 114 cases of MAHC.

A second culture on all CSF was practiced between the $3^{\text {rd }}$ and $5^{\text {th }}$ day; they were reported without growth in $56 \%$ of primary isolates (Fig. 2). Antibiotic resistance phenotype of strains isolated in first CSF is shown in figure 3.

\section{Risk factors for severity and mortality}

The cumulative mortality rate was $\times 16.66 / 100$ cases. Higher mortality frequencies were observed among male patients $57.8 \%$, those patients who developed MACS after a neurosurgical procedure $68 \%$, in children carriers of some nosocomial infection added as endocarditis $68.4 \%$; finally, $42 \%$ of mortality was observed among episodes of meningitis due to Gram-negative bacteria, half of them were secondary to $A$. baumannii MDR.

Notoriously, although $75 \%$ of patients with MSSA meningitis associated died; mortality in general by this factor corresponded to $17.6 \%$.

However, only exposure to more than three antibiotics resulted in binary logarithmic regression with the method of successive backward conditional steps with $\mathrm{OR}=5.50(95 \% \mathrm{Cl} 0.996 \mathrm{LS} 30.36)$ sig 0.050 death correlation -847 .

\section{Discussion}

MAHC follow-up studies recorded frequencies of $6 \%$, especially in young children, commonly associated with prolonged permanence of external CSF drainage systems, tumor etiology in children with VPSV mortality of $22 \%{ }^{12}$.

As of 2005, it has been reported that coagulase-negative Staphylococcus and $S$. aureus are associated with
VPSV up to $65 \%$, with an increase in the participation of MRSA in people with chronic processes such as hydrocephalus and in young children. The nosocomial acquisition is usually less severe than that acquired in community that was associated with a hematogenous origi ${ }^{13}$.

To achieve therapeutic levels before surgery, our patients received in $95 \%$ of the time, at least $24 \mathrm{~h}$ of cephalothin prophylaxis for CSF external bypass and for VPSV, latter were of regular type without antibiotic impregnation.

In our study, the average time to develop meningitis associated with VPSV placement was 8 days after device placement, as reported in other studies ${ }^{9}$.

Special attention is required for cases of MSSA infection that had a $75 \%$ mortality rate in spite of vancomycin treatment, some publications have theorized that participation of $P$ Valentin protein in strains of community origin may be of poor prognosis, but in our study lack of molecular biology tool, could had predicted greater severity and mortality was a vulnerability ${ }^{13,14}$.

Against the odds was expected, the predominance of isolated bacteria was mostly Gram-negative with ESBL-producing antibiotic resistance phenotype and A. baumannii MDR.

In one-third of these children, it was necessary to use intravenous and intrathecal colistimethate, which also was not free of resistance in $7 \%$ of the isolates of $A$. baumannii, one of $P$. aeruginosa.

In our hospital, the first case of Acinetobacter baumannii carbapenems resistant was detected in 1999, since then we have observed the dissemination of this agent in all areas of hospitalization for adult and pediatric patients. During 2011 frequency of participation in processes associated with health care, for neurosurgical area corresponded a frequency of $5.6 \%$ and in pediatric area $1 \%{ }^{15}$.

A finding of importance was the isolation of three strains of $E$. meningoseptica, which has been reported in neonatal sepsis outbreaks and is considered to be a Gram-negative agent sensitive to vancomycin ${ }^{16}$.

Mortality in our study for $A$. baumannii corresponded to $21 \%$, while in other publications, it corresponded between $10 \%$ and $71 \%$ even with use of colistimethate as a salvage treatment $t^{17,18}$.

Although 11 cases had no growth of bacteria in CSF, we decided to analyze them, because we found bacteria present in Gram stains reviewed by at least two infectious pediatrician. This parameter has been shown to be useful in up to half of the cases of meningitis in which cultures had no bacterial growth but with chemical findings suggestive ${ }^{19}$. 
We suggest that the lack of growth of bacteria in blood and CSF was probably secondary to the previous use of antibiotics, on average three except among episodes of Candida etiology that received seven antibiotics as a mean for infectious processes of nosocomial bacterial origin.

Limitations and biases of this study are based on the availability for determination of lactate, procalcitonin, and C-reactive protein in CSF, by our laboratory. Not all bacterial strains could be subjected to a regular determination of sensitivity to bacterial agents, especially colistimethate.

With the exception of colistimethate, all antibiotics used were of generic origin, at appropriate doses, and in duration. We also do not have molecular tools for microbiological diagnosis to determine specifically types of resistance.

In addition, the inability to analyze biofilms in shunts and venous catheters prevents knowing the type of biofilm and the extent of antibiotic therapy as well as the possibility of permanence right there. Moreover, finally, in limitation of hospital resources such as availability of operating rooms, surgical shifts, and access by relatives of patients to pay for VPSV antibiotics impregnated and external drainage systems of CSF.

\section{Conclusions}

It was remarkable the participation of $A$. baumannii MDR, especially in cases where the patient was exposed to broad-spectrum antibiotics, for these cases, although colistimethate can be a salvage treatment, it is an option that already shows resistance and has been transferred to other Gram-negative bacteria.

In our population, the etiology of MAHC by Gram-positive bacteria was associated with a higher mortality risk, associated with other nosocomial infections.

To reduce bacterial resistance, in the future, we must adhere to recommendations of management guidelines for meningitis, in particular, shorten the time of exposure to external drains of CSF and use VPSV impregnated with antibiotics to limit re-infection.

It is essential to always count in hospital units with molecular tools to identify antibiotic resistance.

\section{Acknowledgment}

This research project was carried out without support from external financiers. We declare that there is no conflict of interest. The work group would like to thank the Microbiology Laboratory staff at the Civil Hospital of Guadalajara "Fray Antonio Alcalde", for their invaluable help.

\section{Ethical disclosures}

Protection of human and animal subjects. The authors declare that no experiments were performed on humans or animals for this study.

Confidentiality of data. The authors declare that they have followed the protocols of their work center on the publication of patient data.

Right to privacy and informed consent. The authors declare that no patient data appear in this article.

\section{References}

1. Tunkel AR, Hasbun R, Bhimraj A, Byers K, Kaplan SL, Scheld WM, et al. 2017 infectious diseases society of America's clinical practice guidelines for healthcare-associated ventriculitis and meningitis. Clin Infect Dis. 2017;64:e34-65.

2. Kim HB. Nosocomial meningitis: moving beyond description to prevention. Korean J Intern Med. 2012:27:154-5.

3. Lozier AP, Sciacca RR, Romagnoli MF, Connolly ES Jr. Ventriculostomy-related infections: a critical review of the literature. Neurosurgery. 2002;51:170-81.

4. Piatt JH Jr., Carlson CV. A search for determinants of cerebrospinal fluid shunt survival: retrospective analysis of a 14-year institutional experience. Pediatr Neurosurg. 1993;19:233-41.

5. Choux M, Genitori L, Lang D, Lena G. Shunt implantation: reducing the incidence of shunt infection. J Neurosurg. 1992;77:875-80.

6. Sherrod BA, Arynchyna AA, Johnston JM, Rozzelle CA, Blount JP, Oakes WJ, et al. Risk factors for surgical site infection following nonshunt pediatric neurosurgery: a review of 9296 procedures from a national database and comparison with a single-center experience. J Neurosurg Pediatr. 2017;19:407-20.

7. Kim JH, Desai NS, Ricci J, Stieg PE, Rosengart AJ, Härtl R, et al. Factors contributing to ventriculostomy infection. World Neurosurg. 2012; 77:135-40.

8. Red de Vigilancia ROVE; 2015. Available from: http://www.gob.mx/salud. [Last accessed on 2018 Nov 02].

9. Srihawan C, Castelblanco RL, Salazar L, Wootton SH, Aguilera E, Ostrosky-Zeichner $\mathrm{L}$, et al. Clinical characteristics and predictors of adverse outcome in adult and pediatric patients with healthcare-associated ventriculitis and meningitis. Open Forum Infect Dis. 2016;3:ofw077.

10. García CM. Infecciones relacionadas con los sistemas de drenaje de líquido cefalorraquídeo. Enferm Infecc Microbiol Clin. 2008;26:240-51.

11. Rodríguez Guardado A, Blanco A, Asensi V, Pérez F, Rial JC, Pintado V, et al. Multidrug-resistant acinetobacter meningitis in neurosurgical patients with intraventricular catheters: assessment of different treatments. J Antimicrob Chemother. 2008:61:908-13.

12. Topjian AA, Stuart A, Pabalan AA, Clair A, Kilbaugh TJ, Abend NS, et al. Risk factors associated with infections and need for permanent cerebrospinal fluid diversion in pediatric intensive care patients with externalized ventricular drains. Neurocrit Care. 2014;21:294-9.

13. Aguilar J, Urday-Cornejo V, Donabedian S, Perri M, Tibbetts R, Zervos M, et al. Staphylococcus aureus meningitis: case series and literature review. Medicine (Baltimore). 2010;89:117-25.

14. Torres $\mathrm{C}$. Lectura interpretada del antibiograma de cocos gram positivos. Enferm Infecc Microbiol Clin. 2002;20:354-64.

15. Morfín-Otero R, Alcántar-Curiel MD, Rocha MJ, Alpuche-Aranda CM, Santos-Preciado JI, Gayosso-Vázquez C, et al. Acinetobacter baumannii infections in a tertiary care hospital in Mexico over the past 13 years. Chemotherapy. 2013;59:57-65.

16. Jean SS, Lee WS, Chen FL, Ou TY, Hsueh PR. Elizabethkingia meningoseptica: an important emerging pathogen causing healthcare-associated infections. J Hosp Infect. 2014;86:244-9.

17. Kim HI, Kim SW, Park GY, Kwon EG, Kim HH, Jeong JY, et al. The causes and treatment outcomes of 91 patients with adult nosocomial meningitis. Korean J Intern Med. 2012;27:171-9.

18. Karaiskos I, Galani L, Baziaka F, Giamarellou H. Intraventricular and intrathecal colistin as the last therapeutic resort for the treatment of multidrug-resistant and extensively drug-resistant Acinetobacter baumannii ventriculitis and meningitis: a literature review. Int J Antimicrob Agents. 2013;41:499-508.

19. Brouwer MC, Tunkel AR, van de Beek D. Epidemiology, diagnosis, and antimicrobial treatment of acute bacterial meningitis. Clin Microbiol Rev. 2010;23:467-92. 